\title{
Higher education teachers in Portugal use technology in their educational activities: Myth or Reality?
}

\author{
Paula Peres \\ CICE-ISCAP / IPP, Porto, Portugal \\ pperes@iscap.ipp.pt
}

\author{
Fernando Moreira \\ IJP, UPT, Porto, Portugal \\ IEETA, UA, Aveiro, Portugal \\ fmoreira@upt.pt
}

\author{
Anabela Mesquita \\ CICE-ISCAP / IPP, Porto, Portugal \\ Algoritmi RC, Portugal \\ sarmento@iscap.ipp.pt
}

\begin{abstract}
Technologies are being introduced in our everyday life, including schools and in particular classrooms. Teachers are trying to make the most of web 2.0 tools and social media. However, we are not sure if, in fact, teachers are using these technologies and if when they do, if they do so with pedagogical purposes or to help them to manage the learning process or to replace some obsolete technologies by more modern ones but without learning objectives. To contribute to this question a questionnaire was developed and administered to teachers from higher education. Results show that there is still a long way to go before saying that teachers are fully using and taking the advantages of technologies in the classroom.
\end{abstract}

Keywords - higher education, teachers, technologies, web 2.0, tools, pedagogy.

\section{INTRODUCTION}

The emergence of new technologies and their application in all sectors and dimensions of our everyday life, the change in the behaviour of society in general and in the younger generation in particular, require higher education institutions to "look" for a different way of teaching. The younger generation that arrives now to higher education are those for whom the $9 / 11$ is history. For them, the world is a place where a conversation can be anywhere and at any time. They are a group which fully uses social media for contact and being in touch. Prensky calls them the "digital natives" [1]. These youngsters have grown up in an immersive computing environment. They come to class armed with smartphones, laptops and iPods. And this has significant implications for higher education, namely on teaching methodologies [2].

According to [3], educational systems in general and those of higher education in particular did not evolve as expected due to the adoption of technology and virtual teaching/learning approaches, e-learning, m-learning [4], u-learning [5]. These although used, they are not sufficiently exploited. Teachers to not use their great potentialities neither explore them according to the objectives they were created for. This statement is complemented by the prediction of the futurist Thomas Frey, who postulates "in 14 years it will be a big deal when students learn from robot teachers over the internet."

In this context, learning in the future will be determined by personalization and creativity as indicated in [6], [7], and [8].
With the same perspective, in an interview in 1988 [9] Isaac Asimov predicted that, "computing could allow such a personalized, one-teacher-one-student experience to be available to the masses, replacing or supplementing the oneteacher-many-students experience of most classrooms. "

Due to the different rhythms and approaches implemented by the different actors in higher education (students, teachers, institutions) the use of the web 2.0 tools is serving as a compromised solution. For instance, in [10], one of the arguments presented is the change in the role of the teacher when he/she uses web 2.0 tools in the teaching - learning process. This document quotes an OECD report "New Millennium Learning

in Higher Education" [11], where the authors make the assumption that the majority of teachers in higher education is a digital immigrant due to their age. However this is not true when it comes to their technological competences.

The number of web 2.0 tools and social networks is very high and thus it is necessary to promote and explain how these can be used as well as what kind of pedagogies should accompany their implementation in a classroom. Web 2.0 can be defined as " $a$ second generation in the development of the World Wide Web, conceived as a combination of concepts, trends, and technologies that focus on user collaboration, sharing of usergenerated content, and social networking." [30], [34]. However, it is not enough to have these tools available. It is necessary to select the best pedagogical model and approach to use them with the objective to improve the students' learning curve. In this context, the SAMR model (Substitution, Augmentation, Modification, Redefinition Model) [12] is an adequate model to observe / verify how the use of these technologies can affect the teaching-learning process. This model shows the progression that the adopters of the educational technologies follow when they use the technologies in the teaching-learning process.

One important question is the lack of robust theoretical, technological and pedagogical frameworks of how and which web 2.0 tools to use in an educational environment in order to face the challenges of todays' society. As a result, educators / trainers / teachers in different educational levels are forced to adopt and to rethink their teaching approaches while using the new technologies and taking into consideration the challenges of the knowledge society. 
The natural organization of the web 2.0 tools and social networks to be adopted in the teaching and learning process is through the use of the Revised Bloom's Taxonomy [13]. However, before seeing if the tools used are in line with this or with other classification, we need to know how and which tools are used by the teachers in higher education.

The questions that we ask ourselves at this point is "Are technologies being used in the classroom?"; "Are teachers using them?" and if not, why?

In this paper we present a study done with teachers in order to understand how they use technologies in the classroom with the students and why they use them. The paper is organized as follows: in the next section present the Bloom's Taxonomy as well as the technologies in education, and the challenges teachers are facing with their introduction in the classroom and in the pedagogy. Section 3 presents the research design and section 4 the results and its discussion. We conclude with the summary of the main findings as point directions for future research.

\section{BACKGROUND}

\section{A. Revised Bloom's Taxonomy}

Bloom et al. [14] proposed a cognitive taxonomy that is "is a multi-tiered model of classifying thinking according to six cognitive levels of complexity. Throughout the years, the levels have often been depicted as a stairway, leading many teachers to encourage their students to "climb to a higher (level of) thought.". The Revised Bloom's Taxonomy was introduced by Anderson et al. [15]. The Revised Taxonomy has incorporated student-centred learning prototypes into the original Taxonomy, which improves students' comprehension of and accountable for their own learning, cognition, and thinking. Basically, Bloom's six major features were changed from noun to verb forms. The new levels are: Remembering (to recall facts, basic concepts, or retrieval of material.); Understanding (to explain ideas, concepts, or construct meaning from written material or graphics.); Applying (to use information in new situations such as models, diagrams, or presentations.); Analysing (to draw connections among ideas, concepts, or determining how each part interrelate to an overall structure or purpose.); Evaluating (to justify a stand or decision; to make judgements based on criteria and standards through checking and critiquing); and Creating (to produce new or original work). However, in contrast to the original Taxonomy, the Revised Taxonomy [16] allows the categories to overlap one another [16], which allows to develop the necessary competences and skills that a student needs to master in the 21st century [17]: “(i) Foundational Literacies (How students apply core skills to everyday tasks) (How students approach their changing environment)."

The mapping of the web 2.0 tools in the Revised Bloom's Taxonomy is an open process and without formalization; however there are some proposals that can be used as a guide to help teachers in their adoption. In [18], [19] and figure 1 one can find proposals of a wide variety of tools that can help to accomplish each of the levels defined in [16]. Nevertheless, the way how you will use technology is more important than the technology itself, when you are choosing the best web tool to reach some Bloom's levels.

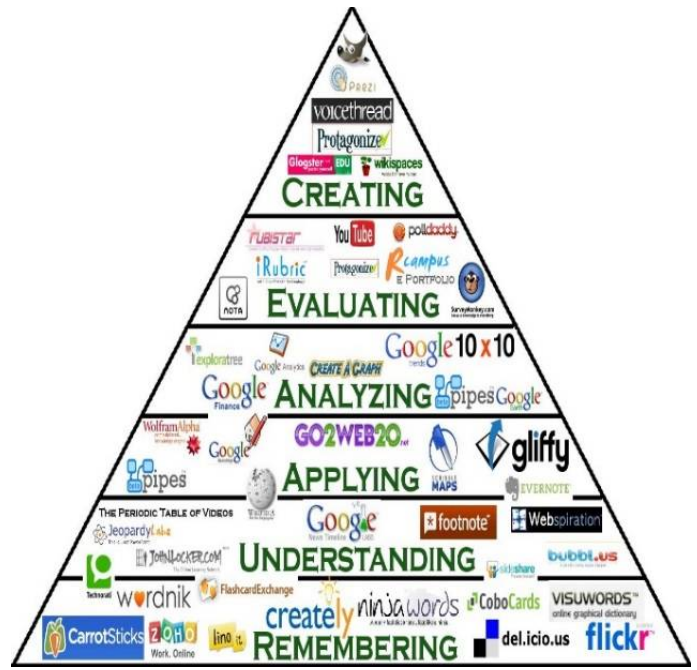

Figure 1. Version adapted from the one created by the University of Southern Indiana (www.usi.edu) [31]

\section{B. The use of Web 2.0 tools in higher education from the perspective of teachers}

Teachers have the perception that web 2.0 tools such as YouTube, Skype, Facebook, Google Docs, Word Press, Blogger, Wikipedia, among others allow users to create and publish content online easily and also to connect to other people with common interests [20]. According to [21] these tools can be used to develop new learning strategies which allow students to be more motivated and stimulate self-learning.

The adoption of these tools in higher education also presents some constraints. For example, factors such as lack of time and training, according to [22] were the most important ones to prevent the use of these tools. However, in the study presented by this author, some very positive aspects were also identified, namely $75 \%$ of teachers state that the use of these tools are beneficial for the students and $83 \%$ referred that the use improved the interaction between teacher and students.

The study presented in [23] shows that teachers stated very positive perceptions of the pedagogical benefits and of the importance of web 2.0 tools in the teaching and learning process. Including the interest to develop more competences in order to integrate in a more efficient way these tools to support and complement the instruction in the classroom.

In another study presented in [24], authors explore the teaching best practices with web 2.0 tools as well as the benefits and barriers associated to their use. The results of this study show that the most important benefits of the use of the web 2.0 tool are: (i) interaction, communication and collaboration, (ii) knowledge creation and (iii) easy to use and flexibility. The most important barriers include the uneasiness with the exposure of sharing and technical problems.

\section{Barriers to adoption of instructional technology}

The use of technology in education in general and in higher education in particular faces a set of barriers that are often not perceived by teachers when they use or attempt to use them in their classrooms. In [25] two-order barriers are presented: "(i) 
First-order barriers are external to the individual and the job and typically involve unavailable resources (e.g. lack of equipment, time, or training), and (ii) Second-order barriers are internal to the individuals and their professional roles and often involve beliefs about teaching, beliefs about technologies, established practices, and unwillingness to change.". In addition to external and internal barriers, the author defines, after an extensive bibliographical research that the issues of technology adoption, in higher education, result in a list of barriers grouped into five categories: (i) technology, (ii) process, (iii) faculty, (ix) environment, and (v) administration. Each of these categories is subdivided into subcategories, for example, category (i) includes the following subcategories: Access to technology, Reliability, and Complexity, while category (ii) includes the following subcategories: Project management, Support (Faculty support, Staff support, Student support), and Faculty professional development (Effectiveness of professional development, Focus of professional development, Pedagogy and instructional technology, Type/Format of professional development offered), etc. For more detail see [25].

In a later study [26], this author studies the problem of adoption including two fundamental questions, self-efficacy and the background of teachers, as other barriers in the adoption of new technologies in the teaching-learning process, since changes are necessary, not only in technologies to be adopted, but also in the pedagogy to use them. The proposed solution to overcome these barriers, in particular the last two, is to consider teacher comfort levels regarding technology and pedagogy and to apply Rogers' theories of innovation diffusion [27]. The classic adoption curve indicating a small number of individuals adopting the innovation early (left tail), followed by the majority of adopters. So to characterize it we can again use the adoption curve of innovation from Rogers. He classifies people in certain situations during the process of adoption of some new idea, as Innovators, Early adopters, Early Majority, Late Majority and Laggards. Those adopting last form the right tail of the curve, as you can see at figure 2 .

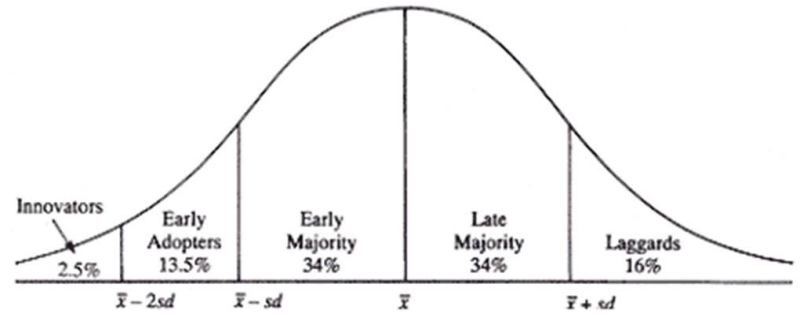

Figure 2. Rogers' curve adoption of technology [27].

Rogers in [27] shows that slightly more than $15 \%$ of teachers can be categorized as "Innovators" or "Early Adopters".

Innovators represent those who are always in the front line to adopt a new trend. They usually have a high level of education, social mobility and receive more information from the outside environments [27]. An innovator is important in the diffusion of new ideas and innovations that they bring from outside systems [27]. Then there are the so called Early Adopters. This group is characterized by following new ideas when the time is right and usually have a higher level of education [27]. The class of the early adopters, more than any other, has a higher level of opinion leaders in most systems. They look at the innovators to receive advice and information about innovation. They are respected by their peers and they know that in order to maintain the respect that they have earned and to maintain the central position that they have in their communication net, they have to make decisions about the innovation. The early adopters help diminishing the uncertainty that results from the application of new ideas with the opinions that they collect form their peers.

The Early Majority is the following group. They reflect more and prefer that others adopt innovations first [27]. The early majority tends to be the bigger group and they usually reflect a lot before completely adopt a new idea. Generally they tend to follow the innovation, but they rarely are the ones that originate the innovation.

Finally the Late Majority. They are very reluctant to innovate, and have to be convinced, through public opinion, to join efforts on developing a new idea [27]. This could happen due to economic reasons or because of community pressure. Peer motivation is necessary to impel the adoption of an innovation. Uncertainties have to be eliminated so that the late majority feels safe in the adoption. Finally, there are the Laggards. The laggards tend to be characterized as an even more reluctant public to change. They are attached to tradition and become suspicious of all types of change. For laggards decisions must be made based on what has been done in the pass. Their resistance could be entirely rational, so they tend to demand assurance of the success of the idea before they adopt it.

To better understand this idea, in [26] an example is presented that addresses the two perspectives, technological and pedagogical. The use of an online discussion through a LMS depends on the comfort of the teacher with his / her skills in the use of the LMS; if they are low, will present resistance in its use. On the other hand, if the teacher is asked to use a new pedagogical approach, for example, in an online discussion, it will compel the teacher to use new practices, namely in the way he has to prepare the learning activity and its evaluation. In this context, if the teacher is not comfortable with this type of methodology he / she will offer resistance in their adoption. In conclusion, it is necessary to take into account that the use of technology in the teaching and learning process, according to [26] "requires a combination of pedagogical and technological comfort."

\section{RESEARCH METHODOLOGY}

The purpose of this section is to describe the procedures used to collect data to answer the questions: "Are technologies being used in the classroom?"; "Are teachers using them?" and if not, why?

The approach used was a quantitative one and data was collected through structured questionnaires. Data collected for quantitative research through the use of questionnaires requires special care because it is not enough to collect responses about the issues of interest, it is also important to know how to do statistical analysis for proper results validation. Aspects such as the sample size, the way the questionnaire is prepared, the questions formulation, data analysis, error margins, the selection of individual process of who should compose the sample, among 
other things, are important and they should be taken into account for any investigation [28]. This method is recommended when you want to know a population, to analyse social phenomena and, in cases where it is necessary to inquire a big number of people about a certain subject. The questionnaire before being delivered was subjected to the evaluation of four experts in the field.

The questionnaire had 3 groups of questions: 1) Biographical data such as gender, age, level of education, year of conclusion, educational institution where the education degree were obtained; 2) Data about the curricular units taught, institution where he/she works, for how many years the person teaches, if the respondents had already had training to use the technologies with students, if the person would like to have such training and if yes, in which area; 3) and finally questions about how the respondent use the technologies in the classroom and why (or why not) he/she uses them. Data collected were pooled and treated by using the IBM SPSS Statistics 24.0 software.

The questionnaire was available online and teachers from both higher education sub systems in Portugal (Universities and Polytechnics) as well as public and private sector, were invited to answer.

\section{ANALYSIS AND DISCUSSION OF RESULTS}

In this section we discuss the results obtained with the questionnaires. This section is divided into three subsections corresponding to the $3 \mathrm{sub}$ sections of the questionnaire.

\section{A. Biographical data}

The study sample consists of 109 teachers, 54 male and 53 female. The majority of the respondents have between 40 and 60 years old $(70 \%)$. The majority of respondents $(65 \%)$ have a $\mathrm{PhD}$ which is usually recent (obtained after 2010). The Universities mostly referred as the ones where the $\mathrm{PhD}$ was obtained are: University of Vigo (Spain), University of Minho and University of Aveiro. Those with a Master or an undergraduate degree are around $14 \% .8 \%$ of the respondents have a post-doctorate.

\section{B. Data about curricular units, institution and use of technologies}

$35 \%$ of the respondents work at the Polytechnic Institute of Porto (public institution) while 23\% work at the European University (private institution).

The majority of the respondents also refers working for more than 15 year (figure 3 ) and more than $50 \%$ already had training about how to use technologies in the classroom (figure 4).

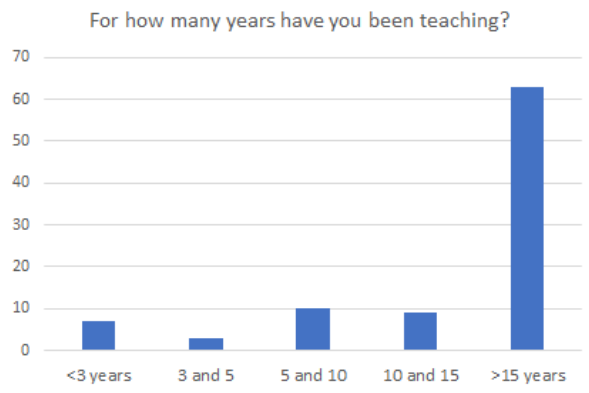

Figure 3. Time for the use of technology by teachers

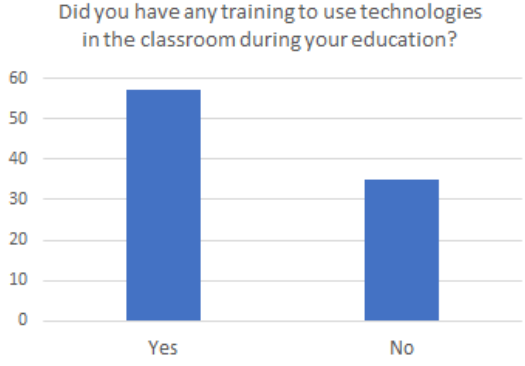

Figure 4. Teachers' training

When asked if they would like to have some training about how to use technologies in the classroom, the majority of those that answered said yes(21 persons out of 35) (figure 5).

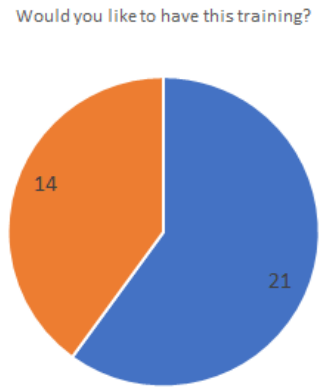

Figure 5. Willingness to have training

Among the participants who indicated that they would like to have more training to use technology, the areas that stand out most are for pedagogical use in language teaching and elearning, office package (especially Excel), applications related to financial area. They also would like to use the technology to establish better collaboration and interaction with the students, for the production and edition of media contents and also for IT improvement as the creation of web pages.

\section{The use of technologies}

The majority of the respondents says that they use very often the technologies in the classroom (figure 6, answers 4 and 5). The technologies mostly used are the data projector, the laptop and the computer (figure 7;1 represents never - left side and 5 represent always - right side). The tablet and TV are seldom used.

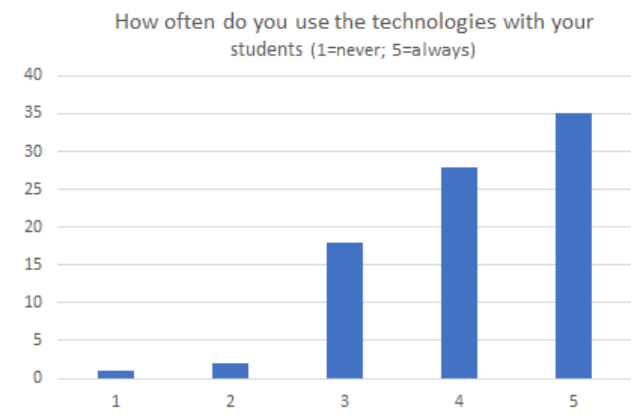

Figure 6. Frequency of the use of technology 


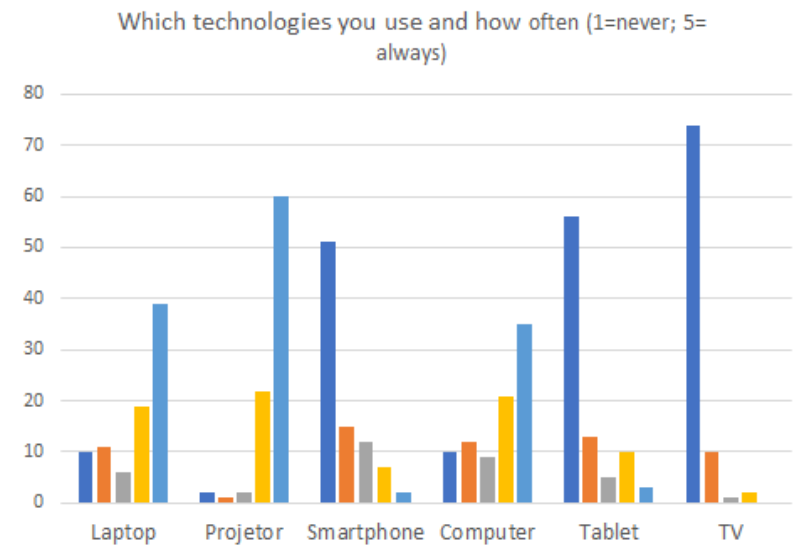

Figure 7. Type of technology used

We also asked which applications teachers use with the students and how often. Figure 8 presents the results obtained. In this question we used the classification advanced in [32] which classifies tools as content production (e.g. Google docs, Prezi, twitter, Wordpress, Blogger), communication (synchronous and asynchronous) (e.g. Messenger, Hangout, Skype, Google+, Facebook [33], Whatsapp, Snapchat, Instagram, Linkedin, Viber), share (e.g. YouTube, Dropbox, Slideshare, Onedrive, Google drive), reference management (Mendely, Zotero, EndNote) and others (e.g. Moodle, Lime survey, b-on). Here the column on the left represents "never" (1) while the column on the right represents "always" (5)).

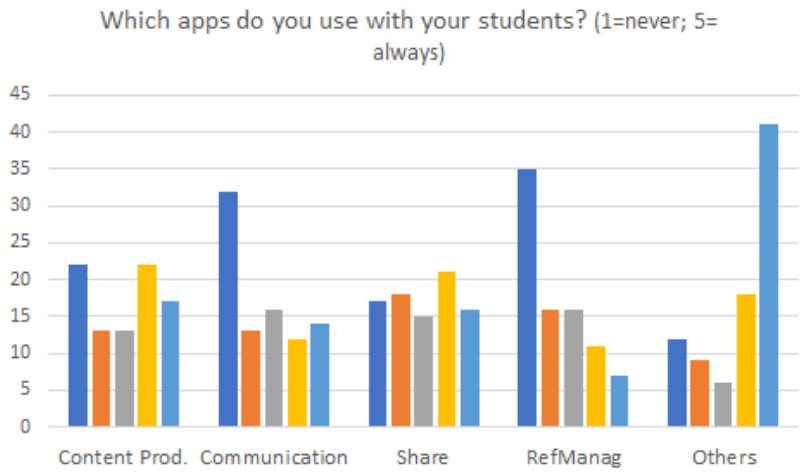

Figure 8. Applications used

Among teachers who said that use technological applications for teaching purposes, the ones that were cited most often in descending order are Moodle (28), Google Docs (24), Dropbox (24), Google Drive (15), Facebook (19), Skype (17), b-on (15), Prezzi (14), End Note (12), One Drive (9), Messenger (9), Power Point (8), WhatsApp (7), Mendeley), Hangou (6), LimeSurvey (5), Slideshare (5) and LinkedIn (4). In addition to these, others appeared less frequently such as Zotero, Scielo, YouTube, SPSS, Outlook, Vimeo, Google Scholar, Meo Cloud, Piazza, Twitter, Glogster, We Transfer, SABI and SAGE. It is curious to note that the first application to be referred is a Learning Management System and the next 3 are mostly used to share files and contents. If we compare the results in figure 8 as for communication with the ones mentioned above, we can see that when Facebook is referred we might think that it is used not as a communication tool but maybe as a space for a group and sharing of contents. The application to manage references are the ones less referred by the teachers.

The last 2 questions of the questionnaire were open and our objective was to understand why or why not teachers used the technologies. The reasons advanced to explain why they do not use (or seldom use) the technologies in the classroom are: technologies were not applicable to the subjects they taught or that they were not necessary or even that the applications they used were enough, especially Moodle (this explain the high rate of "others" in figure 8). Some also responded that it was because they were not trained to use them or that they did not know the purpose of the applications. It was also mentioned the fact that they found the face-to-face contact with the students very important and sometimes this is lost due to the use of the technologies.

As for the reasons to use the technologies teachers claimed that it was for the easy creation and storage of files, for the ease and speed in the communication with the students, for allowing the collaborative and participative learning among the students themselves and the teacher and student relationship, making possible an extension to the access to study contents, through the elaboration of more dynamic classes that attract the attention of the students, allowing the implementation of more efficient collaboration and evaluation methodologies, for the possibility of elaboration of materials that can be used later or passed on to other students, among others.

\section{Discussion of results}

According to the results, none of the answers, especially in the open answers, mention the existence of a concern in presenting any guiding reference for the adoption of the tools in the learning activities, that is to say, that the majority of the teachers do not prepare their curricular units taking into consideration or selecting the most adequate tool to develop the competences that they want their students to develop. This observation is reflected in the first four tools mostly used (Moodle, Google Docs, Dropbox, Google Drive), that is, the concern is to maintain the traditional model of teaching and learning, because as stated in [29] "The last technological Disruption in teaching more than 500 years ago. Until then, the role of the 'lecturer' had been clear - the word's source being the Latin 'reading', meaning to 'read.' ". Teachers, mostly use the tools only to make available material in digital format, and for various platforms.

Another observation that can be drawn is the set of barriers, which implicitly can be found in the open answers. The top two are self-efficacy and teachers' background. These two barriers are evident when teachers indicate that "the tools were not applicable to the subjects they taught, or that they were not necessary...", underlies the self-efficacy barrier, and "Some also responded that it was because they were not trained to use them or that they did not know the purpose of the applications", underlies the background barrier. Both barriers are explicit here, because the amount of tools available would, in almost all areas, allow them to be adopted. However, this adoption would mean a change in the pedagogical model used, and would require 
training, so it is easier to respond that it is not necessary, or that they do not have adequate training.

\section{CONCLUSIONS}

The world and society are changing in all sectors, but in a different speed. The current trend of change relates to the digital transformation that is based on four pillars: Big Data, Cloud Computing, Mobile Connectivity, and Social. This transformation is taking time to reach the education sector. In this context, a study was developed in higher education teachers in Portugal to understand how they use technologies in their teaching activities.

Without surprise, we could attest that, in general, teachers are using technology. They use mostly PCs and laptop. They are using mostly to share contents. So they do not need too much training. If so, they only could reach the first level of the Bloom's taxonomy. If they want to achieve a higher level of thinking they need to prepare more complex learning activities supported by technology. As future work we will try to discover why they aren't using technology in a more complex way. Some questions arise, such as: they do not use technology because they do not know how to use them? Do they feel that they will need pedagogical training? They are not available to spend their time "out-of-the class" to interact with their students online? What kind of administrative and institutional support should be provided? What kind of incentives should be given to the teachers? The results found in this work are the starting point for further studies in the field of the use technology to support learning process.

\section{REFERENCES}

[1] M. Prensky, « Digital Natives, Digital Immi grants. On the Horizon,” 9(5), 2001, pp. $1-6$

[2] A. Mesquita, F. Moreira, P. Peres, "The future of higher education students' views about challenges promoted by technologies," accept for publication, WorldCist2017, 2017.

[3] J. Gomez, J.F. Huete, O. Hoyos, L. Perez, D. Grigori, "Interaction System Based on Internet of Things as Support for Education," Procedia Computer Science 21, 2013, pp 132 - 139

[4] M. Sharples, J. Taylor, G. Vavoula, "A Theory of Learning for the Mobile Age," 2007.

[5] B. Bomsdorf, "Adaptation of Learning Spaces: Supporting Ubiquitous Learning in Higher Distance Education," 2005.

[6] M. Bulger, "Personalized Learning: The Conversations We're Not Having,“ Working Paper, 2016, https://datasociety.net/pubs/ecl/PersonalizedLearning_primer_2016.pdf

[7] F. Moreira, M. J. Ferreira, A. Cardoso, "Higher education disruption through IoT and Big Data: A conceptual approach," Lecture Notes in Computer Science, Springer, 2017, (accept for publication)

[8] A. Mesquita, F. Moreira, P. Peres, "The Customized xLearning Environment Model - Meeting the needs and expectations of students". Paper accepted for publication in the International Journal of Online Pedagogy and Course Design (IJOPCD), 2017. http://www.igiglobal.com/journal/international-journal-online-pedagogy-course/1183

[9] I. Asimov, "The Promise of Personalized Learning," Interview with Bill Moyers, PBSChen, M., Mao, S., Liu, Y. (2014). Big Data: A Survey Mobile. Netw Appl 19: pp 171-209. DOI 10.1007/s11036-013-0489-0

[10] G. Conole, P. Alevizou, A literature review of the use of Web 2.0 tools in Higher Education," 2010, http://files.eric.ed.gov/fulltext/EJ1086976.pdf

[11] OECD, "New Millennium Learners in Higher Education: Evidence and Policy Implications, “ CERI, 2009, http://www.nml conference.be/wp - content/uploads/2009/09/NML - in - Higher Education.pdf

[12] R. Puentedura, "SAMR", https://sites.google.com/a/msad60.org/technology-is-learning/samrmodel

[13] L. Anderson, D. Krathwohl, "A Taxonomy for Learning, Teaching and Assessing: A Revision of Bloom's Taxonomy of Educational Objectives: Complete Edition," New York: Longman, 2001.

[14] B. Bloom, M. Engelhart, E. Furst, W. Hill, D. Krathwohl, "Taxonomy of educational objectives: The classification of educational goals," New York: David McKay Company, 1956

[15] L. Anderson, D. Krathwohl, P. Airasian, K. Cruikshank, R. Mayer, P. Pintrich, J. Raths, M. Wittrock, "A taxonomy for learning, teaching, and assessing: A revision of Bloom's taxonomy of educational objectives," (Complete). New York: Longman, 2001.

[16] D. Krathwohl, "A revision of Bloom's Taxonomy: An overview. Theory into Practice," 41(4), 2002, pp. ,212-218.

[17] World Economic Forum, "New Vision for Education: Fostering Social and Emotional Learning Through Technology," 2016, http://www3.weforum.org/docs/WEF_New_Vision_for_Education.pdf

[18] J. Gonzalez-Major, A. Albright, "Modifying Bloom's Taxonomy to Meet 21st Century " Pedagogies," 2008, http://www.dartmouth.edu/ jmajor/DesignProjects/Publications/digitalT axonomy.pdf

[19] A. Churches, "Edorigami, blooms taxonomy and digital approaches," 2007, http://edorigami.wikispaces.com/Bloom $\% 27 \mathrm{~s}+$ and $+\mathrm{ICT}+$ tools

[20] A. Weller, "The use of Web 2.0 technology for pre-service teacher learning in science education," Journal of Research in Teacher Education, 2, 2013, pp. 40-46.

[21] Redecker at al., "Learning 2.0 - The use of social computing to enhance lifelong learning," European Commission, Joint Research Centre, Institute for Prospective Technological Studies (IPTS), 2010, Seville, Spain.

[22] S. Estable, "Web 2.0 use in higher education," European Journal of Open, Distance, and eLearning,(2), 2014, http://www.eurodl.org/?p=current\&article=655.

[23] S. Yuen, "Perceptions, interest, and use: Teachers and web 2.0 tools in education," International Journal of Technology in Teaching and Learning, 2, 2011, pp. 109-123

[24] J. An, K. Williams, "Teaching with Web 2.0 technologies: Benefits, barriers, and lessons learned," International Journal of Instructional Technology and Distance Learning, 7(3), 2010, pp. 41-48.

[25] P. Reid, "Categories for barriers to adoption of instructional technologies."Education and Information Technologies 19(2), 2014, pp. 383-407.

[26] P. Reid, "Supporting instructors in overcoming self-efficacy and background barriers to adoption." Education and Information Technologies, 22(1), 2017, pp. 369-382.

[27] E. Rogers, "Diffusion of innovations," New York, 1995, The Free Press.

[28] L. Campenhoudt, R. Quivy, "Manual de Investigação em Ciências Sociais," Gradiva Publicações, 2008.

[29] R. Buckley, "Why the education sector is ripe for digital disruption," 2015, http://www.i-cio.com/management/insight/item/why-educationsector-is-ripe-for-digital-disruption

[30] Dictionary.com, Web 2.0, 2017, http://www.dictionary.com/browse/web$\underline{2-0}$

[31] D. Krathwohl, L. Anderson, "Bloom and Web 2.0". 2010, http://www.mmiweb.org.uk/web20/bloomweb20.html

[32] P- Peres, P. Pimenta P. "Teorias e Práticas de b-Learning". Edições Sílabo, 2011

[33] J. Martins, R. Goncalves, J. Pereira, T. Oliveira, M. P. Cota, "Social networks sites adoption at firm level: A literature review," In Information Systems and Technologies (CISTI), 2014 9th Iberian Conference on (pp. 1-6). IEEE.

[34] J. Martins, R. Gonçalves, J. Pereira, M. Cota, "Iberia 2.0: A way to leverage Web 2.0 in organizations," In Information Systems and Technologies (CISTI), 2012 7th Iberian Conference on (pp. 1-7). IEEE. 